\title{
Editorial: Living Labs
}

\section{Chris McPhee, Editor-in-Chief Mika Westerlund and Seppo Leminen, Guest Editors}

\section{From the Editor-in-Chief}

Welcome to the September issue of the TIM Review. This month's theme is Living Labs and it is my pleasure to welcome our guest editors, Mika Westerlund, Assistant Professor at Carleton University's Sprott School of Business in Ottawa, Canada, and Seppo Leminen, Principal Lecturer at the Laurea University of Applied Sciences and Adjunct Professor in the Aalto University School of Business in Finland.

This issue contains seven articles written by experts from Belgium, Canada, Finland, Germany, the Netherlands, Spain, and the United Kingdom, who have researched and participated in living labs. They share their research, experience, and insights to help further our understanding of the benefits, methodologies, and types of living labs.

This issue also includes a report on a recent TIM Lecture by Louis Lamontagne, President and CEO of LTL Global Innovations and Management, who spoke about born-global companies from the perspective of an entrepreneur in the pharmaceutical industry. The term "born global" refers to businesses that aim to address a global market from day one (Tanev, 2012; timreview.ca/ article/532).

Born Global is also the theme of the October issue and the guest editor will be Tony Bailetti, Director of the Technology Innovation Management program (TIM; carleton.ca/tim) at Carleton University.

As always, we welcome your feedback, suggestions for future themes, and contributions of articles. We hope you enjoy this issue of the TIM Review and will share your comments on articles online. Please also feel free to contact us (timreview.ca/contact) directly with feedback or article submissions.

\section{Chris McPhee}

Editor-in-Chief

\section{From the Guest Editors}

The theme of this issue is Living Labs, which is an evolving and noteworthy topic in the field of open and user innovation. The number of living lab experiments that have emerged in recent years is substantial and continues to rise while there are currently over 300 living labs at ENoLL (European Network of Living labs) in Europe and worldwide. This is hardly a surprise, because ad-hoc types of user-driven and user-centered activities are increasingly seen as important for companies and public organizations globally as a way to generate innovative improvements and novel solutions to real-world problems. Despite the considerable business and government interests in living labs, there are few research articles on the topic available to date.

The TIM Review attempts to bridge this gap by providing both theoretically and practically oriented articles for managers and innovation developers as well as researchers and other parties of interest. The articles in this issue are representative of living lab activities taking place today in selected European countries, but readers elsewhere will identify comparable configurations from their own countries.

One of the greatest challenges today is the definition of living labs because of their variety and the continuous evolution of the related concepts and methods. We define living labs as physical regions or virtual realities, or interaction spaces, in which stakeholders form public-private-people partnerships (4Ps) of companies, public agencies, universities, users, and other stakeholders, all collaborating for creation, prototyping, validating, and testing of new technologies, services, products, and systems in real-life contexts. They are used for the development of communities for the use of innovation.

A living lab is not a testbed. A living lab turns users from observed subjects to active co-creators of value and explorers of emerging ideas, breakthrough scenarios, and innovative concepts. A living lab is an experiential environment where users are immersed in a creative social space for designing and experiencing their own future. Policy makers and citizens can use living labs to design, 


\section{Editorial: Living Labs}

Chris McPhee, Mika Westerlund, and Seppo Leminen

explore, experience, and refine new policies and regulations in real-life scenarios before they are implemented.

In this issue of the TIM Review, we examine the living lab phenomenon from a variety of perspectives. The authors of these seven articles provide insights into how organizations, citizens, and nations can derive value from living labs. The articles examine theoretical frameworks, categorizations, experiences, and implications related to living labs. These seven articles make a substantive contribution to our limited knowledge of living labs.

The first article, by Seppo Leminen, Mika Westerlund, and Anna-Greta Nyström, depicts living labs as networks characterized by open innovation. The article is based on an extensive multiple-case study that investigates network members' roles in living labs in four countries. It introduces four different types of living labs and describes their key characteristics. The article suggests that living labs designers and participants should understand the overall purpose of the living lab and which party drives the network anchored around the living lab.

In the second article, Esteve Almirall, Melissa Lee, and Jonathan Wareham establish a framework to map different user-innovation methodologies. The framework positions the methodologies in an innovation landscape, which is based on characteristics identified from four cases representing living lab practices in Belgium, Finland, Spain, and Sweden. The article makes a significant contribution by summarizing the most common European living labs approaches and describing their merits and appropriateness.

Bernhard R. Katzy develops in the third article a business excellence model that shows processes through which living labs deliver high-potential investment opportunities. This article is one of the first attempts to identify the business models of living labs; there are few good examples of those models to date. The article concludes that living labs provide extensive support through "lab" infrastructure and that financing remains a formidable challenge.

The fourth article by Hans Schaffers and Petra Turkama explores how living labs can form collaboration networks to support small firms and other actors to engage in cross-border collaboration and to accelerate the development and acceptance of innovations. It elaborates both strategic and operational collaboration issues. The provide lessons learned on the role of living labs in developing and operating cross-border networks for systemic innovation.

In the fifth article, Dimitri Schuurman and Lieven De Marez report the experiences of three Flemish living lab initiatives with a panel-based approach. The article provides a customer-characteristics framework that guides user involvement in living labs. The authors present three living lab cases to illustrate the characteristics of a specific type of living lab: the panel-based living lab. They conclude the work by comparing the value aspects of panel-based and traditional living lab approaches.

In the sixth article, Ingrid Mulder discusses "living methodologies", which are methods and tools necessary in living labbing. These methodologies address adhoc living activities by citizens or user communities that are not connected to existing living labs. The author reports on three cases from the Netherlands where citizens co-developed their city. The article concludes that living labbing helps in inspiring and informing the design of innovative services that aim to enrich our daily life and environment.

In the last article, Veli-Pekka Niitamo, Mika Westerlund, and Seppo Leminen provide insights of a smallfirm perspective to innovation in living labs. The article reports a case of a small energy IT provider, which participated in an EU-funded multinational living labs initiative to develop energy-efficiency management solutions. The article describes the living lab activities that took place and discusses the perceived challenges of applying living labs for small business management.

It is evident that open innovation and user-driven methods continue to evolve and increase in popularity. There will be many exciting opportunities for companies, nonprofits, and government agencies to adopt innovative methods that help them to create novel products, services, and solutions that meet latent customer needs or improve the world together with citizens. We hope that you enjoy the issue and consider utilizing the potential and opportunities of living labs and living labbing in your organization.

\section{Mika Westerlund and Seppo Leminen Guest Editors}




\section{Editorial: Living Labs}

Chris McPhee, Mika Westerlund, and Seppo Leminen

\section{About the Editors}

Chris McPhee is Editor-in-Chief of the Technology Innovation Management Review. Chris holds an MASc degree in Technology Innovation Management from Carleton University in Ottawa and $\mathrm{BScH}$ and MSc degrees in Biology from Queen's University in Kingston. He has over 15 years of management, design, and content-development experience in Canada and Scotland, primarily in the science, health, and education sectors. As an advisor and editor, he helps entrepreneurs, executives, and researchers develop and express their ideas.

Mika Westerlund, D. Sc. (Econ.) is an Assistant Professor at Carleton University's Sprott School of Business in Ottawa, Canada. He previously held positions as a Postdoctoral Scholar in the Haas School of Business at the University of California Berkeley and in the School of Economics at Aalto University. Mika earned his doctoral degree in Marketing from the Helsinki School of Economics. His doctoral research focused on software firms' business models and his current research interests include open innovation, business strategy, and management models in high-tech and service-intensive industries.

Seppo Leminen, D. Sc. (Econ.), Lic. Tech., holds positions as Principal Lecturer at the Laurea University of Applied Sciences and Adjunct Professor in the Aalto University School of Business in Finland. Seppo holds a doctoral degree in Marketing from the Hanken School of Economics and a licentiate degree in Information Technology at the Helsinki University of Technology. His research and consultation interests include value co-creation and capture with users as well as relationships, services, and business models in marketing. He runs various living lab and business model projects relating to ICT.

Citation: McPhee, C., M. Westerlund, and S. Leminen. 